\title{
Mental Health Awareness and the Importance of Socialization for Education in the Post-COVID19 Era
}

\author{
Janelle Resch* and Ireneusz (Eric) Ocelewski
}

University of Waterloo, Canada

*Corresponding author: Janelle Resch, University of Waterloo, 200 University Ave. W., Waterloo Ontario, N2L 3G1, Canada.

\begin{abstract}
Due to the shift of civilization from the Industrial Age to the Information Age, science, technology, engineering and mathematics (STEM) literacy has become a necessity in the twenty- first century. However, in order to learn and contribute to the STEM community, one has to be in a state of good mental health. Where 'good mental health', is defined as one who has developed a set of healthy coping strategies, while being in a positive learning environment, and having a social support system. Traditionally, universities have been the venue of such higher learning but COVID19 has introduced some unexpected challenges. This paper briefly discusses the importance of socialization, specifically for young mathematicians, scientists and engineers, and potential consequences of reduced social exposure in the post-COVID19 digital era.
\end{abstract}

Keywords: Mental health; STEM; COVID19; Amygdala; Autism-spectrum disorder; Mixed reality

\section{The Importance of Socialization}

A common complaint from students at the post-secondary level relates to many mathematicians are socially-inept." The comparison of STEM individuals to those of autism-spectrum disorder (e.g., Asperger syndrome) is not uncommon, especially by the student body and entertainment media such as The Big Bang Theory. Typically, students label and associate 'social-ineptness' when their peers or professors seem to lack empathy, have abnormal social interaction(s), minimal social interactions(s), or scant communication(s) [1]. Although this may initially sound o ensive, it is supported by modern research.

For example, one study was conducted in 2001 with a group of 840 students from Cambridge University (454 males, 386 females) where each student were given an autism-spectrum quotient test (AQ) [2]. This test attempts to measure autistic traits for 'individuals of normal intelligence.' The researchers found that scientists obtained higher AQ scores compared to non-scientists. In particular, it was found that within scientific fields, mathematicians had the highest AQ scores. Physical scientists, computer scientists and engineers also had higher scores compared to students in 'human or life-centered' sciences (specifically medicine, veterinary science and biology) [2]. These results also agreed with an earlier study carried out in 1998 again at Cambridge University. It was found that autism occurred \significantly more often in families of students in the fields of physics, engineering, and mathematics" [3]. Overall, \it seems that people who have autistic traits may find it easier or more natural to work in these fields," said Simon BaronCohen; the co-director of the Autism Research Centre at Cambridge University [4].

The authors found these studies to be quite intriguing since it has also been revealed that on average, millennials spend around 
seven to eleven hours a day in front of some sort of computer screen (desktop, tablet, smartphone, etc.) [5]. This indicates that the younger generations are not socializing (face-to-face) nearly as much as previous generations. This is further exacerbated due to the COVID-19 pandemic and that much of the education systems have had to migrate to remote online instruction. Hence, present generations of children do not gain as much experience socializing in-person with others, which can be quite problematic. With waves of SARS-CoV-2 expected to be an issue for two years [6], there will be significant psychological side effects. The prevalence of depressive symptoms has already increased three-fold in the United States, for instance [7]. Learning how to read body language, especially facial expressions, is an essential part of social and physiological development [8]. Facial expressions for instance are a form of nonverbal communication that conveys emotion. In fact, facial expressions are one of the primary ways that emotion is communicated between individuals [9]. Being able to witness a person's reaction activates mirror neurons, allowing one to simulate what another is experiencing [10].

Furthermore, one's response to this stimulus is reflected in one's own facial expressions thereby completing the feedback loop. A part of the brain that plays a key role in facial recognition is the amygdala [11]. As we currently understand, the amygdala, which is part of the limbic system in the brain, processes emotional reactions, memory formation and decision making [12]. It plays an essential role in storing and forming memories associated with emotional experiences [13]. Researchers speculate that the amygdala may be highly involved in recognizing negative emotions [14]. Individuals with a larger amygdala are better able to recognize the emotional state of others through facial expressions. Therefore, researchers hypothesize that larger amygdalae may be an indication of greater emotional intelligence. The development of the amygdala is correlated with involvement in social networks that are conducted in-person. More specifically, the size of the amygdala increases according to the number of social interactions a person has over their development period. The variations and complexity of different social groups also influences this development $[15,16]$.

In addition, several studies have indicated that the amygdala has a significant role in mental states and hence, poor mental health [17]. For instance, some studies have shown that children with anxiety disorders usually have a smaller left amygdala. An overactive left amygdala seems to be associated with border-line personality disorder and depression; whereas an underactive left amygdala seems to be correlated with psychopathy. In general, the amygdala seems to be connected with social anxiety, obsessive compulsive disorders, social phobias, bipolar disorder and not surprisingly, autism-spectrum disorders [17-20]. Studies have demonstrated that people with autism-spectrum disorders have a di cult time identifying facial expressions. In particular, some research has suggested that such disorders escalate due to a lack of physical social experience: \the development of face perception and social cognitive skills are supported by the amygdala fusiform system, and that deficits in this network are instrumental in causing autism" [21].

Due to these studies and findings, we hypothesize that all mathematicians are \a little bit autistic" and potentially, more susceptible to poor mental health. Consider that to be a successful mathematics student, the student has to spend more time alone doing problems compared to individuals studying less technical fields. To complete an undergraduate degree in mathematics, at least four years has to be dedicated to such learning. Typically, such an endeavour starts around the age of 17 - 19, sometimes even younger. If a student then enrolls into a masters or doctorate degree, that is another two to six years of intensive isolated work. In total (not including post-doctoral fellowships), that is approximately four to ten years during the period in one's life where individuals grow into the people they want to become [22]. This is a lot of time spent being alone. This may imply that the parts in the brain responsible for empathy and socialization, such as the amygdala, will not sufficiently develop; especially compared to people with more complex social networks and interactions.

If this hypothesis is true, we may have a serious problem. If a STEM background is necessary in the twenty first century, a time where computers and the Internet are an integral part of our lives, will people start becoming less socially aware and less empathetic (for some more information see [23])? Could the people who are needed to solve the world's biggest problems be more likely to suffer from psychological disorders? These are questions that we cannot afford to ignore or avoid.

This hypothesis also seems to be connected with a major complaint people, and especially women have regarding mathematics or generally STEM education: it is lonely. Social interaction is more important biologically for women than it is for men [24], and women are more likely to change academic and professional paths when compared to men due to their lack of confidence [25]. Perhaps these are reasons why there are more men in fields like maths, physics and engineering. A potential solution may sound simple: make mathematics and the education system more social with the help of technology (which will be the focus of future research).

Mixed reality (MR) has much potential because it allows for the creation of three-dimensional (3D) interactive learning environments giving users the ability to interact socially and manipulate their virtual environments. For STEM sub reject matter, this is especially useful for students, teachers and researchers since it allows one to play with a problem. This results in better understanding of the theory and corresponding applications. Further leveraging the software used to develop MR content can also be of great value to students because it teaches them how to approach computation and general STEM problems. This is further enhanced when such interactions include multi-user 
spaces that would foster the necessary social development. In the authors' opinion, we need to create an open, positive, social learning environment to nurture healthy educated people. Virtual environments in the post-COVID-19 era present an optimal approach to address the issues outlined above.

\section{Acknowledgement}

None.

\section{Conflict of Interest}

No conflict of interest.

\section{References}

1. American Psychiatric Association (2013) DSM 5. American Psychiatric Association.

2. S Baron-Cohen, S Wheelwright, R Skinner, J Martin, E Clubley (2001) The autism-spectrum quotient (AQ): Evidence from Asperger syndrome/high-functioning autism, malesand females, scientists and mathematicians. Journal of autism and developmental disorders 31(1): 5-17.

3. Baron-Cohen Simon, Patrick Bolton, Sally Wheelwright, Victoria Scahill, Liz Short, et al. (1998) Autism occurs more often in families of physicists, engineers, and mathematicians. Autism 2(3): 296-301.

4. (2011) It's a Fact: Scientists More Likely to Be Socially Inept. Times Higher Education.

5. (2010) Generation M2: Media in the Lives of 8- To 18-Year-Olds. Henry J.Kaiser Family Foundation. http://kff.org/other/event/generation-m2media-in-the-lives-of/.

6. Moore KA, Lipsitch M, Barry JM, Osterholm MT (2020) Part 1: the future of the COVID-19 pandemic: lessons learned from pandemic in uenza. COVID-19: the CIDRAP viewpoint. Center for Infectious Disease Research and Policy.

7. Ettman CK, Abdalla SM, Cohen GH, Sampson L, Vivier PM, et al. (2020) Prevalence of Depression Symptoms in US Adults Before and During the COVID-19 Pandemic. JAMA Network Open 3(9): e2019686-e2019686.

8. Zeman Janice (2020) Emotional Development - Early Infancy (birth-six Months), Later Infancy Months) (7-12). < http://psychology.jrank.org/ pages/212/Emotional Development.html>

9. Rinn William E (1984) The neuropsychology of facial expression: a review of the neurological and psychological mechanisms for producing facial expressions. Psycho logical bulletin 95(1): 52-77.

10. Ferrari Pier Francesco, Vittorio Gallese, Giacomo Rizzolatti, Leonardo Fo-gassi (2003) Mirror neurons responding to the observation of ingestive and communica-tive mouth actions in the monkey ventral premotor cortex. European Journal of Neuroscience 17(8): 1703-1714.

11. Carlson, Neil R (2010) Physiology of behavior Ed., 10. Boston: Allyn and Bacon.
12. K Amunts, O Kedo, M Kindler, P Pieperhoff, H Mohlberg, et al. (2005) Cytoarchitectonic mapping of the human amygdala, hippocampal region and entorhinal cortex: intersubject variability and probability maps. Anatomy and embryology 210(5-6): 343-352.

13. Maren Stephen (1999) Long-term potentiation in the amygdala: a mechanism for emotional learning and memory. Trends in neurosciences 22(12): 561-567.

14. Adolphs Ralph (2002) Neural systems for recognizing emotion. Current opinion in neurobiology 12(2): 169-177.

15. Bickart Kevin C, Christopher I Wright, Rebecca J Dauto, Bradford C (2010) Dickerson, and Lisa Feldman Barrett. Amygdala volume and social network size in humans. Nature neuroscience 14(2): 163-164.

16. Buchanan TW, Tranel D, Adolphs R (2009) The Human Amygdala (eds. Whalen, P.J. and Phelps, E.A.) 289318, Guilford, New York, USA.

17. Donegan Nelson H, Charles A Sanislow, Hilary P Blumberg, Robert K Fulbright, Cheryl Lacadie, et al. (2003) Amygdala hyperreactivity in borderline personality disorder: implications for emotional dysregulation. Biological psychiatry 54(11): 1284-1293.

18. Blair RJR (2008) The amygdala and ventromedial prefrontal cortex: functional contributions and dysfunction in psychopathy. Philosophical Transactions of the Royal Society B: Biological Sciences 363(1503): 2557-2565.

19. YI Sheline, D M Barch, J M Donnelly, J M Ollinger, A Z Snyder, et al. (2001) Increased amygdala response to masked emotional faces in depressed subjects resolves with antidepressant treatment: an fMRI study. Biological psychiatry 50(9): 651-658.

20. Blumberg Hilary P, Joan Kaufman, Andrs Martin, Ronald Whiteman, Jane Hongyuan Zhang, et al. (2003) Amygdala and hippocampal volumes in adolescents and adults with bipolar disorder. Archives of General Psychiatry 60(12): 1201-1208.

21. Schultz Robert T (2005) Developmental Decits in Social Perception in Autism: The Role of the Amygdala and Fusiform Face Area. International Journal of Developmental Neuroscience 23(2-3): 125-141.

22. Jay Meg (2012) The dening decade: why your twenties matter and how to make the most of them now. Grand Central Publishing: New York, USA.

23. (2010) Generation Me: Study Finds College Students Lack Empathy. Education Portal. http://education-portal.com/articles/GenerationMe-Study-Finds-College-Students-Lack-Empathy.html.

24. Brizendine Louann (2006) The Female Brain. New York: Morgan Road, USA.

25. Are women really less condent than men? (2014) CBC Radio's The Current, May 27th. http://www.cbc.ca/books/2014/05/are-womenreally-less-confident-than-men-take-the-quiz-to-find-out.html. 